\title{
Method and Notation Application for Case Model Creation in the Social Sector
}

\author{
Birger Lantow ${ }^{*}$, Johannes Wichmann ${ }^{1,2}$, and Paul Herzog ${ }^{1}$ \\ ${ }^{1}$ University of Rostock, Albert-Einstein-Str. 22, 18059 Rostock, Germany \\ ${ }^{2}$ Wismar University of Applied Sciences, Philipp-Mueller-Str. 14, 23966 Wismar, Germany \\ \{win.office,birger.lantow\}@uni-rostock.de, johannes.wichmann@hs-wismar.de
}

\begin{abstract}
Adaptive Case Management (ACM) is an approach for the management of knowledge-intensive processes. "Case Management Model and Notation" (CMMN) is an industry standard that can be used as a notation for process models in the context of ACM. However, CMMN only specifies a notation. Methods for process elicitation and management have not been well addressed by scientific investigations. This work assesses the method support and the feasibility of ACM on the example of a social care company. This company, on the one hand, represents a typical environment for ACM application and, on the other hand, contains some characteristics that are common for the social care industry. Thus, future development directions, a combined process and case approach for the social care company and an evaluation of existing and proposed methodology are provided in a qualitative way.

Keywords: ACM, Adaptive Case Management, Case Management, Social Sector, Social Companies, Knowledge-Intensive Processes, BPM2.0, BPMN 2.0 CMMN.
\end{abstract}

\section{Introduction}

In times of dynamic competitive conditions, multilayered and variable workflows and increasing dependencies of companies on capabilities, new approaches for the management of processes are necessary to handle the complexity.

Whereas a simple process capture through Business Process Management (BPM) seems to be outdated [1], [2], [3] to address this challenge, enterprise documentation is becoming increasingly important to use dynamic solutions [4], [5]. One approach to managing current, knowledge-intensive processes is Adaptive Case Management (ACM). Just as in the field of business process modeling in the form of business process modeling notation, there is a standard industry notation for process recording in adaptive case management called "Case Management

\footnotetext{
* Corresponding author

(C) 2019 Birger Lantow et al. This is an open access article licensed under the Creative Commons Attribution License (http://creativecommons.org/licenses/by/4.0).

Reference: B. Lantow, J. Wichmann, and P. Herzog, "Method and Notation Application for Case Model Creation in the Social Sector," Complex Systems Informatics and Modeling Quarterly, CSIMQ, no. 21, pp. 34-50, 2019. Available: https://doi.org/10.7250/csimq.2019-21.03

Additional information. Author ORCID iD: B. Lantow - https://orcid.org/0000-0003-0800-7939, J. Wichmann https://orcid.org/0000-0002-0663-5109. PII S225599221900123X. Received: 25 October 2019. Accepted: 27 December 2019. Available online: 31 December 2019.
} 
Model and Notation" $\left(\mathrm{CMMN}^{\dagger}\right)$. However, CMMN defines only one possible notation for process models and hardly considers methods for the collection and management of cases that are of particular importance for knowledge-intensive processes. For this reason, this article examines the research question: Is Adaptive Case Management suitable for use in social settings? The work pursues the goal of proposing a method component, which serves to create initial case templates and the definition of case objectives. It is an extended version of a prior publication [6] at the ManComp 2019 workshop co-located with BIR 2019 in Katowice, Poland. Additions have been made with regard to the implications of the presented case study. In particular, issues with regard to CMMN are highlighted.

To address the research aim appropriately, a company within the social sector was selected as a case study to test the method component. Therefore, the research follows a design-oriented information systems research approach with the underpinning of inductive reasoning. Derived from the findings of the case study, perceptions for the implementation of ACM in the social sector shall be gathered [7]. The corresponding company was selected because it provides two advantages. One the one hand, it represents a common environment for ACM application and, on the other hand, comprises some characteristics that are representative for the social care industry. Thus, future development directions and an evaluation of existing and proposed methodologies are provided in a qualitative way.

Section 2 presents a selection of relevant literature and the principles of ACM as well as a reference to Case Management (CM) in social care. Section 3 introduces a possible solution for a method support for ACM in the social sector. Then, the method support is critically evaluated and extended. The following Section 4 evaluates the extended method in a case study. Section 5 discusses the extension of CMMN with regard to found shortcomings in the case study. Section 6 summarizes the findings, limitations and outlook of this work.

\section{Adaptive Case Management and Social Care Processes}

The following section will describe the relations between ACM and processes in social care. Therefore, the central features of ACM (Section 2.1) are necessary and a distinction to traditional BPM (Section 2.2) is conducted. Subsequently, Section 2.3 provides the relation to social care processes, derived from the findings in Section 2.1 and 2.2.

\subsection{Central Principles of Adaptive Case Management}

The term Adaptive Case Management (ACM) has its roots in the year 2009 and was developed by domain experts because they realized that the traditional operative Business Process Management (BPM) does not fit to the needs of today's knowledge workers anymore [1], [2]. Given that the context and management of working activities as well as environmental changes are increasingly significant, ACM addresses those needs as it manages responsibilities and activities that are required to complete a business case successfully [2], [8].

The innovation changed the management's view, as now a case and not a process is in the focus for illustrating different views on companies' processes. A case consists of a bunch of several tasks. There are planned and unplanned tasks that should fulfill a specific purpose. Each case can be divided into different tasks and processes. Thereby, each case is defined by its purpose and it is possible that one case contains multiple instances [8]. This is comparable to process instances, when processes are performed.

Based on the case term, the case template represents the equivalent of a process model in traditional BPM, whereas the case instance corresponds to a process instance [9]. Assuming that each case instance represents a different or even unique situation, the management of a case

\footnotetext{
${ }^{\dagger}$ https://www.omg.org/cmmn/
} 
instance always takes a specific process flow into account [10]. In the same instance, all accumulated information and data about a task or the case instance itself are stored [8].

ACM enables the knowledge worker to perform configurations of cases, and respectively of tasks, on the fly without support from professional system developers (as a developer configuration activity). It is possible to create a collection of performed and to be performed tasks and to control case handling based on it. By avoiding double and contradictory work, collaboration and performance of the employees are improved. The work results can be optimized with regard to service quality, expenses and time [2], [8].

Kurz and Herrmann present the central principles of ACM implementation [9]. They divide these principles between the areas organization, case handling, and adaption, as presented in Figure 1.

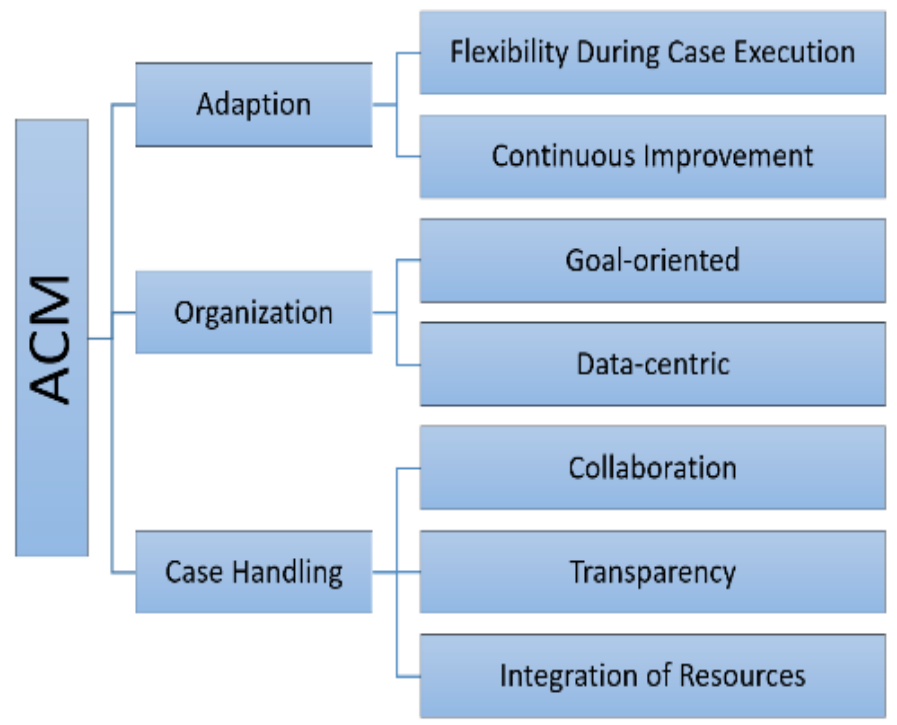

Figure 1. Central ACM Principles, adapted from [11]

In terms of the organization, a case always has at least one goal. The performed tasks contribute to the achievement of the goal and are directly connected to it. Thereby, it is difficult to control a case by a control flow because a case can comprise a high variability while the structuredness is low. Instead, the case process control is data driven. In order to reach the case's goal, tasks are bundled by the case and by case data [2], [9].

By considering the case handling, the knowledge work, or the tasks of a case respectively, are highly collaborative. All employees involved need to communicate with each other, to collaborate and to control the progress [12], [13]. Therefore, collaboration is a focal point of ACM. It can be reached by appropriate tools for social interaction [9]. These tools also need to assure the transparency that is needed for efficient case handling. All required internal and external resources like people and information connected to a case need to be provided in a structured manner. This means that all people involved in a case need to have access to the existing organizational knowledge and the results of case handling [12], [13]. Transparency plays a decisive role prior to, during, and after handling a case instance. The employees need to know the tasks to be performed and their relations to them before the case handling starts. At the same time, knowledge of prior case instances needs to be retrievable [12].

In the context of adaption, the focus is on knowledge work and the system should be designed so that the knowledge worker has the possibility of adapting this system to his/her needs. The consequent aim is that the knowledge worker adjusts the process appropriately, so that efficient processing is possible.

The adaption can be done in two ways. First, it can happen during case execution, which describes the adjustments of the system to a specific case instance. As a result, it is always 
possible to edit the case instance flexibly. Therefore, external or internal events or case-internal findings may be the reason of changes. Moreover, business rules can ensure structured, efficient and targeted process management [3], [9]. The second way refers to the completed case instances and uses the knowledge gained from them to adapt case templates and continuously improve the overall system [12]. Important premises are, that errors are made only once and that frequently used case elements are made available for future case instances. An adjustment can be made for entire case templates or individual case components. This cross-case adaption describes the flexibility of changes in terms of business processes by both, the employees and by the system [9].

\subsection{Distinction between Adaptive Case Management (ACM) and Traditional Business Process Management (BPM)}

While comparing traditional BPM and ACM directly, the different degree of determinacy becomes apparent. In BPM, the deterministic processes can be defined in advance. This requires, that the status of a process is fixed, while modeling it. The problem is that the actual process steps can be very complex and in need of flexibilization, whereas the decisions, rules and all influences that govern the process flow, as well as the mentioned status of the process, have to be predefined [14].

In contrast, ACM is not deterministic. The modeling aim is known, but the path to reach it is non-restricted and it is possible that this path will vary from case to case. In addition, a process in ACM often cannot be stopped because there is no predefined sequence of activities, but orders vary and activities can be processed in parallel [15].

A further development of the traditional BPM, which has similarities with the ACM, is the Business Process Management (BPM 2.0). The basic idea of BPM 2.0 is that employees, as part of their daily work, can independently propose process improvement potentials and make changes. This should result in process innovations, which are the defining goal of BPM 2.0. Often, the process innovations emerge through collaborative work among employees and through jointly developed ideas to improve processes. This should contribute significantly to the identified flexibility deficits in BPM [16].

BPM 2.0 incorporates approaches based on the fundamental principles of the ACM and becomes more flexible, especially because of innovation incentives and motivations for collaborative activities. However, regardless of the approach, BPM 2.0 suits better for repetitive tasks, whereas ACM is intended for knowledge-intensive processes [9], [16], [17].

\subsection{Social Care and Adaptive Case Management}

Case Management (CM) is a standard for work organization in healthcare, family assistance, youth welfare, and care of the elderly [18]. In contrast to ACM, where process control and IT support are the main objectives, CM provides a holistic view of help-organization for a social sub-system in need (generally, these are people or families = clients $\equiv$ case instances). Therefore, case management aims at an efficient and effective use of available resources [19], [20]. Within the social sector (social work and social pedagogy), CM is the common method of work triggered and induced by governmental laws and policies, e.g. in Germany, the United States, and Scandinavia. In terms of treatment cases within the healthcare sector, where regular treatments are not success- or helpful, CM is used to identify groups of patients in need of specialized care [21]. As a result, it will be clarified below whether, based on the previous findings, CM in the social sector makes an IT support by ACM appear appropriate. Therefore, a design-oriented information system research with inductive reasoning is conducted and discussed in the following [7]. 
There are two distinct layers applying CM in the social sector. The first one is the activities of the individual professionals during case work and then, on a higher layer, the second one is the coordination of the resources provided by the different involved professions - the CM process.

A suitable approach for describing casework in the social sector is Müller's circular four-level model [20]. It considers anamnesis, diagnosis, intervention and evaluation as essential activities of casework in the respective sector and is well suited for the argumentative ongoing of this research due to its low granularity. According to Müller's model, the individual steps of action do not follow consecutively in a linear order but should be able to penetrate each other and to start over again [22]. For this reason, problems can arise in rigid process sequences. The fourlevel model shows that steps that ideally should be processed consecutively are often erratic and concurrent. The knowledge of each social worker determines the further steps. Anamnesis, for instance, is inevitably linked to the diagnosis, as an outcome is often anticipated, even without enough information. The process of accepting, conforming and defining a diagnosis proceeds practically parallel to the collection of information, but at different levels [20]. The statement of need for cooperative working in multi-disciplinary teams in terms of case management in the social sector is in line with current research approaches [23], [24].

In addition, the other resources that can be assigned to a particular case also influence the casework. Above all, the client himself, but also his environment and personal network are important and interesting for the case [25]. As a result, due to the subjectivity and variability of the environment, the casework processes are hardly structurable, thus hardly representable in models of activity, and consequently difficult to illustrate via ACM [26].

In contrast, the $\mathrm{CM}$ process, as a comprehensive control tool, prescribes a fixed procedure based on legal requirements for the management and coordination of case processing. A common procedure provides the following steps: (1) determination of case groups/screening, (2) assessment/diagnosis, (3) planning, (4) implementation, (5) monitoring, (6) evaluation and (7) reporting [27], [28]. The step (1), case group determination/screening, serves determining characteristics that justify an application of the $\mathrm{CM}$ for a client and describes the similar cases (in terms of case groups). The screening then uses these characteristics to identify clients for specific case groups. The processing of the steps (2) to (6) is carried out according to the content of the four levels of the Müller-model mentioned above. In contrast to the description of casework, the CM process is not about individual work processes, but about the coordination and control of the activities of several professions in the case. For the adaption of this coordination task, the ACM provides the special role of a case manager [28]. For him/her, in order to be able to effectively carry out his work, the clear delineation of the individual steps is necessary. Nevertheless, these steps have to be run several times during the case implementation and, moreover, are subject to the variability of the environment. The final step (7) is to provide caseby-case documentation and review of the overall impact of the CM.

The description of CM in the social sector suggests a fundamental applicability of the ACM [26], [29]. The characteristics of the application area correspond to those described in Section 2.1, which are identified as appropriate for ACM - the area is collaborative, knowledge-intensive and to a great extent there is no clear flow of control. According to the aforementioned definitions, a concurrent application in casework, where activities cannot be distinguished from one another, will be difficult. In contrast, there is a possible support for the CM process, which has a corresponding variability, requires collaboration and, with the determination of the case group as well as the accountability, contains a case-instance-overarching knowledge protection. While in the clinical sector, an IT support in terms of case management is mainly based on document management and providing the information necessary for coordination and planning [27], both data management and process control are absent in the social area. 


\section{Method Support for Adaptive Case Management}

In order to describe the method support for ACM, the method model by Goldkuhl et al. [30] is used. Here, a method is a composition of so-called method components, where each component addresses a sub-problem of the method application. A method component describes procedures, concepts and a notation. In addition to these method components, a method definition also contains a perspective (in terms of problem definition and scoping), cooperation forms and a framework. The latter is intended for the use-control of the method components. With regard to ACM, the perspectives and concepts were presented according to the current state of science (Section 2.1) and CMMN was introduced as a notation that scarcely considers other method components. To tackle this disadvantage, the process and role model by Hermann and Kurz [9], [31] is selected as appropriate for the method support. This approach contains the peculiarity that it is based on the BPM 2.0 approach and adapted accordingly for ACM. Therefore, Section 3.1 provides a brief explanation of the model and Section 3.2 aims to adjust and extend the method for the social sector appropriately.

\subsection{Method by Kurz and Herrmann}

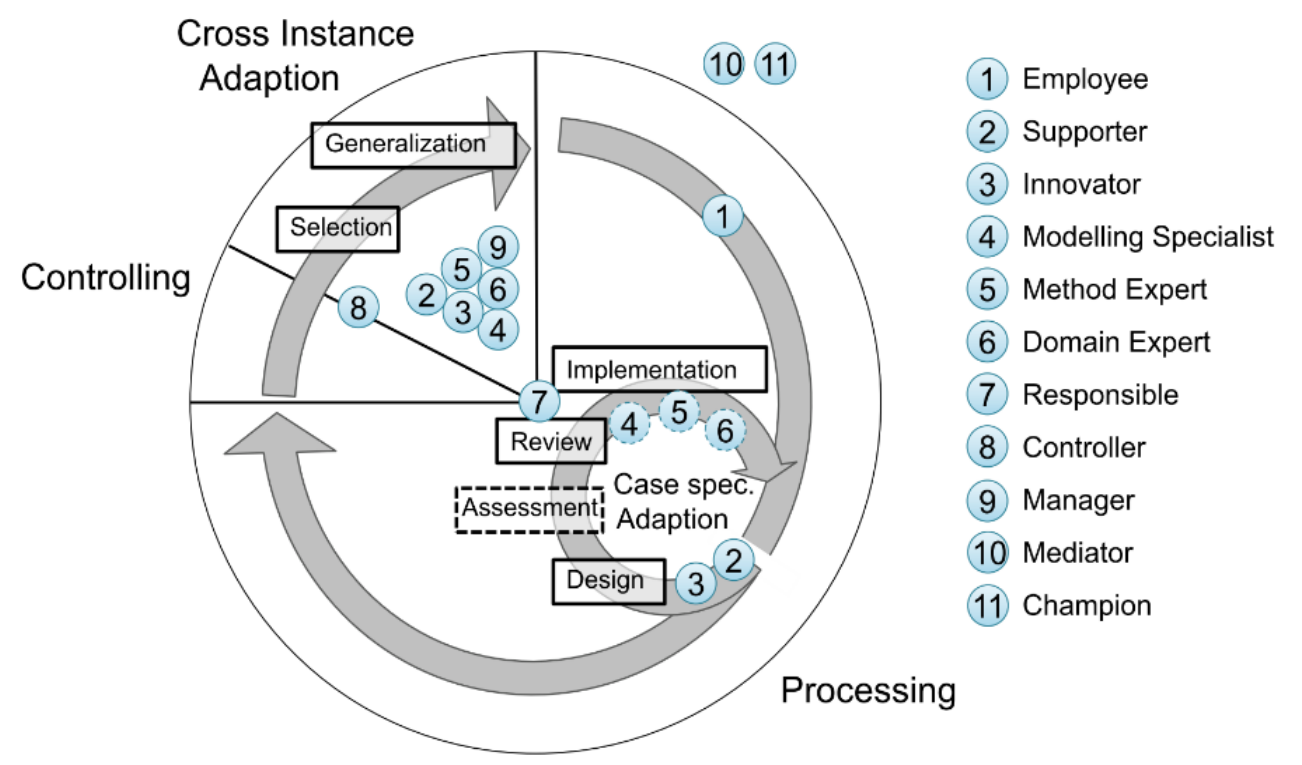

Figure 2. Process and Role Model by Hermann and Kurz, adapted from [31]

The method is described based on a process and a role model (Figure 2). The role model defines the responsibilities in each stage of the ACM process, defining a total of 11 roles. The procedure model describes the tasks involved in the ACM and their sequence. First, in the execution phase, the case template is selected and an instance is created. This is either adapted to the specific case requirements before or during case processing. This happens either with one or more iterations and contains the following advantages: (1) a flexible approach to changing conditions and requirements is possible; (2) improvements can be implemented faster by limiting the scope of functions of individual iterations to be implemented; and (3) the system is accepted better, by the users and by the management [9].

Corresponding adjustments within a case are either directly created by the employees (roles 1 , 2 and 3) or developed collaboratively. In the further ongoing, suggestions for improvement are evaluated by the case officers (roles 6 and 7) and checked for correctness. If the approval (role 7) has been granted, the adaption will be implemented (roles 4 and 5). By considering the simplest case, this happens automatically, for instance, when creating a new process task. In some cases, additional manual development work may be required, such as the provision of complex functionalities [9]. In the control phase, as soon as the case objectives have been completed and 
the case has been closed, the achievement of objectives and the efficiency of the case are assessed. The changes made as part of the case-specific adoption are also evaluated (roles 8 and 9). If sufficient information and approaches for improvement exist for a case report, these can be generalized and made available in the case-by-case adaption for use in future cases. Individual case components or entire case templates and components can be adapted or stored separately as specialized variants [9]. The mediator (role 10) interferes in conflicts, while the champion (role 11) serves as a supporter of the ACM in the company [9].

\subsection{Method Evaluation and Enhancement}

In general, the method by Kurz and Hermann is appropriate for an application in the social sector, but contains some weaknesses:

1. A high level of complexity of the proposed procedure for adaption before or during the case processing is determined, whereas a detailed evaluation of individual method components was not carried out.

2. Method components are also not specified to the extent that procedures within them can be described concretely; the method describes the framework only.

3. The role model, provides the basis to define cooperation forms, but these are also not specified. Hence, how do the roles interact when implementing ACM, is not clear.

4. There are no method components that describe how

a. cases are identified (see (1) Case Group Determination / Screening Section 2.3),

b. initial case templates are created,

c. case objectives are defined,

d. evaluation is performed.

5. The case manager role (Section 2.3) is not depicted, but the role model is too complex to be practicable in small companies.

In order to encounter these deficiencies, expert interviews are conducted in order to obtain appropriate information, which accordingly extends the Kurz and Hermann method so that it is most suitable for the use in the social sector. As stated in the introduction, this research aims to propose a method component that creates initial case templates and defines case objectives. A behavioristic approach via qualitative expert interviews as a cross-section analysis [7], [32] was carried out. In the sense of purposive sampling strategies according to Palinkas et al. [33], collaborative, guided interviews were chosen as means for data collection. The method expert processed them (role 5) with employees (role 1) and associates responsible in dispositive functions (roles 8 and 9) in order to use different, company-internal views for case processing. Concerning the determined procedure of the interview guide, it is based on Prenner [34], who deals with tools for recording business processes through interviews in his research. In addition, the research of Trinczek [35] was used to design the process modeling questions.

Table 1 presents the key questions for the interview. The first and second question What is your profession? and What are your duties? are inherited from Prenner [34]. The third question When a client contacts you, what is happening then? descends from Penner as well and has been formally adapted. The fourth question What activities are being performed, by whom and where? is a combination of three central questions from Trinczek [35]. The original questions are: What is done? (activity), Who performes the activities? (role/person) and Where are the activities performed? (location/organizational unit). With the question Which tools are needed?, the fifth question is developed based on Trinczek [35] and slightly extended. The sixth question is also inherited from Trinczek [35]. The questions seven through ten are case-study-specific, as questions seven and eight delineate the approach from traditional BPM. The questions aim at starting activities that are performed outside a defined control flow. Question nine addresses the goal orientation, the project character of case processing, and the identification of important case objectives. The tenth and last question has a controlling and complementary effect on the 
documentation and should give the person interviewed the opportunity to provide additional information, which is not triggered by the previous nine questions.

Table 1. Interview - Guiding Questions

\begin{tabular}{|c|c|c|}
\hline Question & Comment & Goal \\
\hline 1. What is your profession? & Determine name of profession & Starting conversation \\
\hline 2. What are your duties? & Determine work areas & $\begin{array}{l}\text { Identify all responsibilities of the } \\
\text { employee }\end{array}$ \\
\hline $\begin{array}{l}\text { 3. When a client contacts you, } \\
\text { what is happening then? }\end{array}$ & Procedure of case handling & $\begin{array}{l}\text { First impression of case handling. Is } \\
\text { there a defined control flow? }\end{array}$ \\
\hline $\begin{array}{l}\text { 4. Which activities are performed, } \\
\text { by whom and where? }\end{array}$ & $\begin{array}{l}\text { Reveal responsibilities, } \\
\text { activities and processes, local } \\
\text { orientation }\end{array}$ & $\begin{array}{l}\text { Identify all relevant activities of a } \\
\text { case and determine the location of } \\
\text { performance }\end{array}$ \\
\hline $\begin{array}{l}\text { 5. Which tools and preliminary } \\
\text { work is needed? }\end{array}$ & $\begin{array}{l}\text { Determine preconditions for } \\
\text { activity execution }\end{array}$ & $\begin{array}{l}\text { Understanding of relations between } \\
\text { activities in order to find } \\
\text { dependencies }\end{array}$ \\
\hline $\begin{array}{l}\text { 6. What are triggers for the } \\
\text { activities? }\end{array}$ & Determine trigger and relations & $\begin{array}{l}\text { Intensify relations and presenting } \\
\text { dependencies }\end{array}$ \\
\hline $\begin{array}{l}\text { 7. Which activities can be } \\
\text { performed at an arbitrary point in } \\
\text { time? }\end{array}$ & $\begin{array}{l}\text { Activities that are outside a } \\
\text { defined control flow }\end{array}$ & Show independent activities \\
\hline $\begin{array}{l}\text { 8. Which activities need to be } \\
\text { performed at or until a certain } \\
\text { point in time? }\end{array}$ & $\begin{array}{l}\text { Activities that are outside a } \\
\text { defined control flow but bound } \\
\text { to temporal requirements }\end{array}$ & $\begin{array}{l}\text { Identify temporal requirements of the } \\
\text { case and further specify relations } \\
\text { between the activities }\end{array}$ \\
\hline $\begin{array}{l}\text { 9. Which milestones can be } \\
\text { defined for the case? }\end{array}$ & $\begin{array}{l}\text { Milestones help to control } \\
\text { progress in case handling }\end{array}$ & $\begin{array}{l}\text { Definition of milestones and hence } \\
\text { case objectives }\end{array}$ \\
\hline $\begin{array}{l}\text { 10. Are there activities or relations } \\
\text { that have yet not been mentioned? }\end{array}$ & $\begin{array}{l}\text { Reassurance of the modeling } \\
\text { result }\end{array}$ & Correctness of the resulting model \\
\hline
\end{tabular}

Parallel to the interviews, sketches are made with all tasks and individual relationships. These provide a better overview during the interviews so that interviewers and respondents do not lose the track. The sketches are based on a simplified notation (Figure 3) that is based on CMMN. This simplified notation allows to collect tasks and milestones in order to keep track of process goals and how they can be achieved by task execution. Instead of complex constructs to control the execution of tasks, freely named relations are used in order to collect dependencies between tasks and if possible semantics of these dependencies.

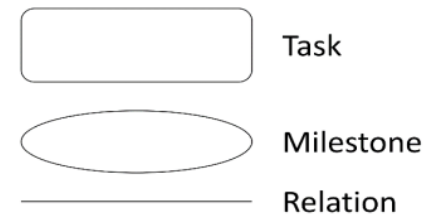

Figure 3. Notation for the case description during the interviews

In order to exclude influences of prior interviews, each interview starts with a new sketch. After performing the interviews, a case template in CMMN notation is created by the method expert.

\section{Case Study}

The case study (in terms of case study based research design) was conducted in cooperation with the GeBEG, the society for child upbringing, health and education Rostock. Mainly, the company works with families, parents, children and the youth welfare office. Together, the case 
assistance for child upbringing was selected for modeling. Therefore, four GeBEG employees were interviewed with the methodology described in Section 3.2. Three of them were social workers (role 1, Section 3.1) and one of the four was one of the company's leaders (role 8 and 9). The method expert (role 5) is external to the company in this case. The formal role of a case manager (Section 2.3) did not exist in the GeBEG, as the cross-profession coordination is provided by the youth welfare office. Following the third interview, it was no longer possible to identify any tasks that were not mentioned yet. For illustration, a part of the initial model created in the 1 st interview using the notation suggested in the previous section is shown in Figure 4. The final result is presented in the description of the case (the model in Figure 5).

Most of the activities have no predefined procedure or order. There are fixed activities and processes, but these relate to specific requirements or specifications by the authorities. Other crucial activities and processes often only emerge spontaneously, for instance, by getting in contact to one or more clients. Through permanently changing circumstances, many cases differ from the general case. This makes it difficult to substantiate the general tasks for a case. Strong external and internal factors can change processes quickly and often.

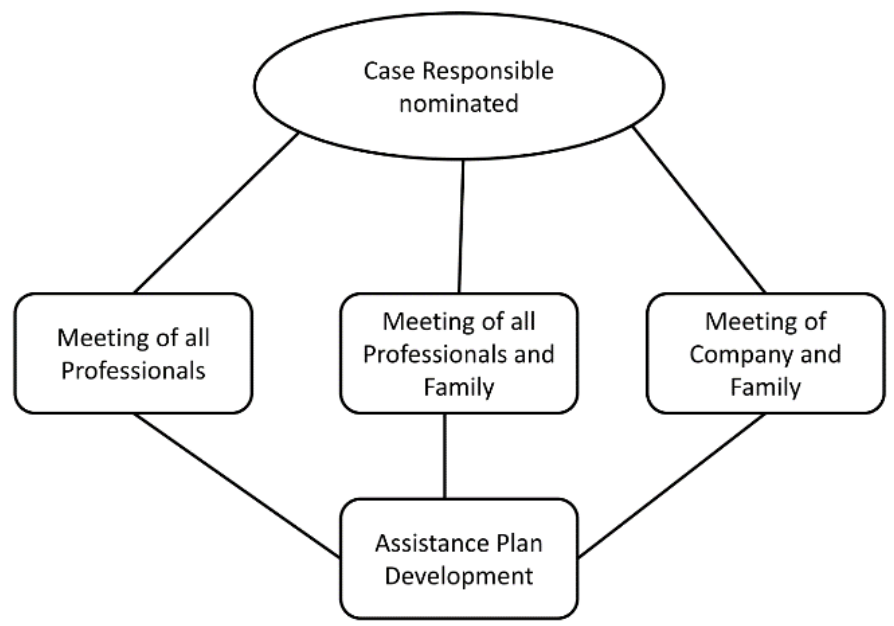

Figure 4. Part of initial model (1st Interview)

In general, all four interviewees described a similar procedure (case template in Figure 5). They stated that the work process started with a first meeting. There are various combinations of participation among the involved parties. Either the first meeting takes place only with the professionals (youth welfare office and GeBEG) or with the professionals and the clients (all participants) and, as a third option, the meeting takes place between the GeBEG and the client. In this first meeting, all participants should get to know each other better and the client's family decides whether they want to accept help from the social worker or not. In addition, if help is appreciated, the content of the help program and corresponding goals for it are defined. Therefore, two of the four interviewees created a genogram (or sociogram) to get a better overview of the case. In the course of the help process, appointments take place, which have to be documented and deducted. Every six months, an assistance plan meeting takes place with the youth welfare office. Two weeks before this assistance plan meeting, the assistance report must be submitted to the youth welfare office. During this meeting, the past assistance period is evaluated and, if necessary, goals are set for a further period. All interviewees indicated on demand that this six-month cycle between the assistance plans is a formal order. During the interviews, it turned out that there is no real conclusion of the case, as long as the help continues. However, the client or the GeBEG can terminate the help program at any time.

As a result (Figure 5), it became apparent that many supporting activities were modeled (to make an appointment, to document, to account the time needed). The issues of anamnesis, diagnosis, intervention and evaluation from the model according to Müller [20] are indirectly reflected. For instance, elements of the anamnesis and diagnosis can be identified in the first 
meeting. In addition, the assistance plan discussion with the aspects of retro perspective and reflection also contain evaluation aspects. The documentation then externalizes the results of the case instances and thus contributes to the reporting goals, which is done by describing the CM process according to Section 2.3. The intervention takes places in the stage meetings with client, but is not further specified there. It also determines that the $\mathrm{CM}$ process, which requires documentation, influences the casework.

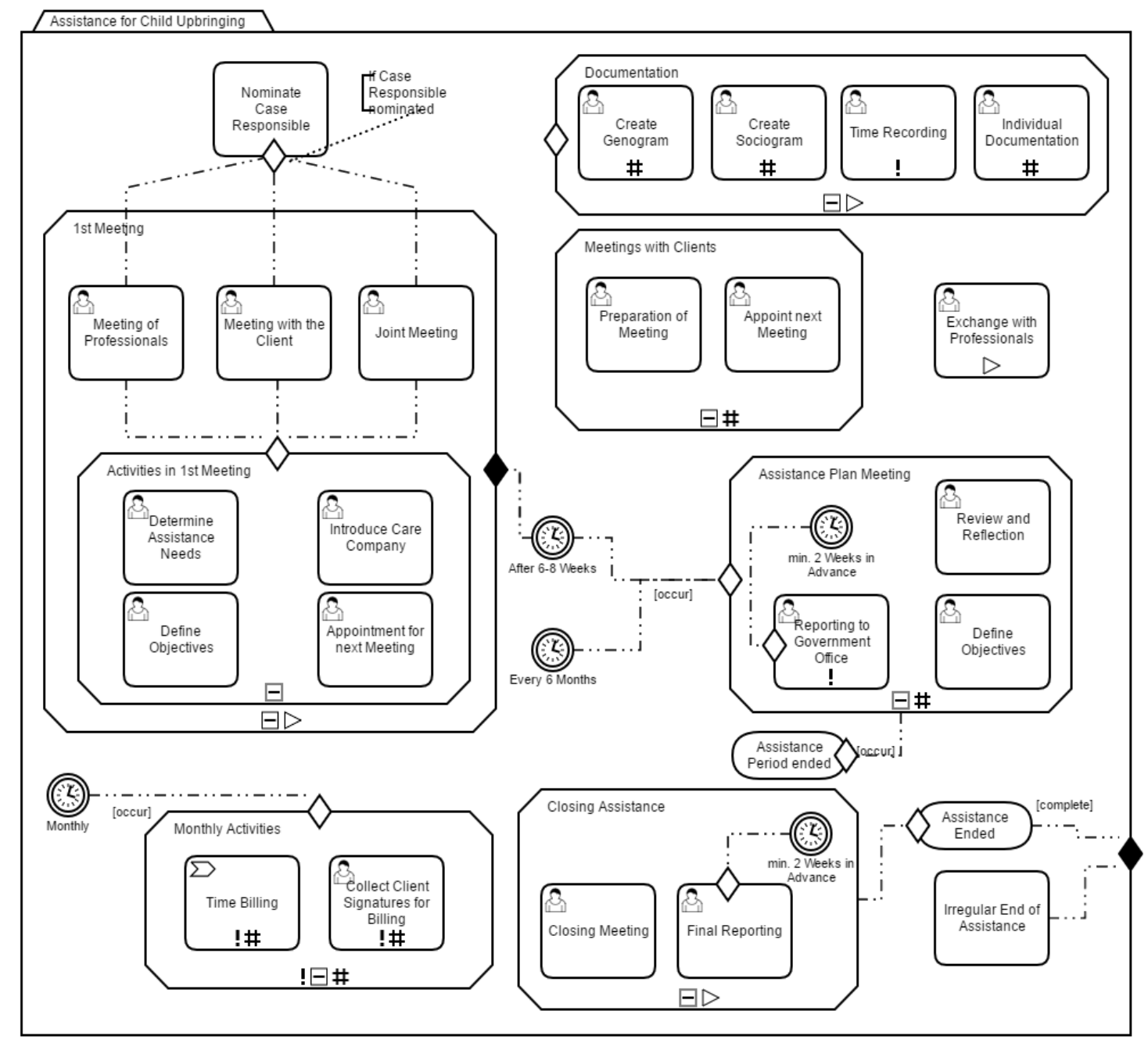

Figure 5. Case Template "Assistance for Child Upbringing" in CMMN

The CM-process in particular involves different organizations and organizational units. Thus, it cannot be modeled by a single organization (unit) using the existing method support. There are approaches to inter-organizational ACM by Hildebrandt et al. [36] and Kurz [37], but these approaches mainly focus on a notation for processes and the assurance of solid process models when modeling in a distributed manner, whereas method components for process elicitation are not considered. Furthermore, with regard to an appropriate notation, organization models might be required. Additionally, the requirements of involved roles for certain activities and stages have not been modeled because of limited CMMN expressivity, for instance, a required involvement of a case manager from the welfare office in certain activities. Also, the participant involvement in the first meeting could not be modeled adequately. Though having one goal $-\mathrm{a}$ commitment to work together in the assistance program - three different activities have been defined in order to express the different role constellations that may be involved ("Meeting of Professionals", "Meeting with the Client", "Joint Meeting"). However, in order to reach that goal, all three involved roles need to express their commitment in order to let the assistance start. This involves collaboration either within the first meeting or as a part of "Exchange with professionals". There are more collaborative activities that involve more than one role, for 
instance, "Review and Reflection" and "Define Objectives" as part of the "Assistance Plan Meeting". Bukhsh et al. already criticised the CMMN limitations for modeling roles and collaborations in [38].

The definition of case objectives is not examined adequately so far. The suggestion by Kurz et al. [11] to introduce milestones to CMMN has been implemented in the current CMMN version. However, the case objectives are domain specific and, regarding this research, the interviewees were not able to define milestones for the case study. Furthermore, objectives may change during case handling, e.g. due to important changes within the social environment of the client. In general, the achievement of case objectives should be traceable by case data since case control is data centric and this could lead to improvements in other cases. Hence, data models should be included in case modeling methods.

While the experts finally agreed on the CMMN model that has been created based on the interviews, they have not been able to interpret the model without explanation by the modeling expert. Hence, there is an understandability issue with regard to the model. If validation of the model is only possible through the filter of a modeling expert this imposes a limitation of the method in general and particularly the validation. This problem has also been indicated by Bukhsh et al. [38] interviewing three process modeling experts with regard to three business process model notations. They rated the understandability of CMMN the worst compared to an extended CMMN by Bukshs et al. and BPMN ${ }^{*}$ with the best understandability. Other authors generally criticize the understandability of CMMN [11], [39], [40]. In addition, our expert interviews indicated that predefined sequences of tasks, thus structured parts of the process, are not visible in the CMMN model.

In consequence, the case study revealed additional weaknesses of existing method support for ACM for the domain of social care compared to those in Section 3.2:

1. Missing method component for inter-organizational case modeling.

2. Limited notation support for roles and organizational structures. Based on:

a. Missing support for role-based process execution constraints,

b. Missing support for collaboration activities.

3. Limited notation support for case objectives.

4. Lack of understandability of CMMN models:

a. Lack of clarity with regard to structured process parts.

Most of the found weaknesses seem to be generalizable, because they are not limited to the situation in social care. Furthermore, notation issues are revealed. Thus, available and important knowledge with regard to the case could not be modeled adequately by the use of CMMN.

\section{Extending CMMN}

A number of scientific publications discussed shortcomings of CMMN. A literature review on these publications can be found in [41]. Generally, there are four approaches to address found shortcomings [41]:

1. Using a reduced set of concepts in order to allow the end-user/knowledge-worker to contribute to the modeling process [39], [40].

2. Extending the CMMN notation with additional concepts [38].

3. Amending CMMN model by concepts from other standards like BPMN and $\mathrm{DMN}^{\S}[42]$, [43] or SBVR ${ }^{* *}$ [5].

4. Transforming CMMN models into other notations for further processing [26], [44].

\footnotetext{
$\$$ https://www.omg.org/bpmn/

$\S$ https://www.omg.org/dmn/

** https://www.omg.org/spec/SBVR/
} 
Considering the experiences from the case study, following approach 1 does not provide a solution to the found shortcomings. Although, a reduced set of concepts generally increases understandability, the main issues were caused by missing concepts (role and organizational models, objectives, activity sequences). A reduced notation has already been used during the interviews and transformed to CMMN based on the experts' statements. Furthermore, approach 4 does not provide a solution because it does not add concepts either.

Considering approaches 2 and 3, the latter should be favorited. Using established standards provides a broad community that is able to model and interpret process models as well as tool support. Therefore, we evaluate in the following, how the third approach can be used to solve the shortcomings of CMMN found in the case study. The current CMMN standard introduced the use of BPMN, DMN, and SBVR in case models. Considering the concepts that are provided by these notations, only BPMN provides roles, role descriptions as well as structured processes by control flow specification as an abstract concept and as a symbol of graphical notation. No additional support is provided by the considered standards with regard to objectives. Thus, amending CMMN by BPMN concepts can generally address the issues 1,2 and 4a, formulated in the previous section. However, according to CMMN standardization, BPMN can only be used to describe automated sub-processes within a case model. In consequence, there is no direct combination of BPMN and CMMN. The case model contains automated tasks which are then specified in a separate BPMN model. The BPMN standard does not refer to CMMN. An overarching structured process containing unstructured parts, as we can see it in the case study example, could not be modeled.

BPCMN suggested by Hinkelmann [42], [43], in contrast, is a notation that provides a free combination of elements of both standards and thus allows modeling a process as mixture of structured and unstructured parts. Furthermore, the approach allows the usage of BPMN-Lanes to assign activities to roles. In the consequence, a BPCMN seems to be appropriate to address issues 2 and 4a. Using BPCMN implies some theoretical and practical limitations. Models that are standard compliant (CMMN, BPMN) can be transformed into executable workflow models on platforms like Camunda, which implement the standards. However, BPCMN proposes the joint usage of CMMN and BPMN in a way that is not part of the standards. Furthermore, while concepts are clear, an extensive description of syntax (allowed combinations of elements of both standards) is missing as well as a direct transformation into executable workflow models. Additionally, no evaluation of the understandability (issue 4) of BPCMN models has been performed. At last there is no defined method component how to decide whether a process part should be modeled in a rather structured way (BPMN elements) or in a rather declarative way (CMMN).

In the following, the case template "Assistance for Child Upbringing" that depicts the resulting model of the case study is transformed into a BPCMN model. The resulting model is shown in Figure 6. The Knowledge Work Designer by Hinkelmann et al. [43] has been used for modeling because it is the only available tool for BPCMN modeling. However, the tool does not support task and stage decorators that have been used for task description in the CMMN model such as Required "!" or Repetition "\#". Therefore, this information is currently not depicted in the BPCMN model. For transformation to BPCMN, those parts of the process that have a clear sequence have been modeled using BPMN control flow relations. BPMN Lanes are used in order to assign roles or organizational units to the process elements. Complex tasks that are unstructured and thus further detailed in CMMN are indicated by a file symbol. The respective CMMN model for each of these tasks is modeled as a stage. Thus, there are stages for "1st Meeting", "Assistance Plan Meeting", and "Closing Assistance". Activation of these stages during process execution is based on the control flow specification. The other stages and tasks can be performed at any time or at specific conditions if a sentry is specified. This includes the stages "Documentation", "Meeting with the Client" and the task "Exchange with Professionals". Except for the tasks that have been used to model the different role constellations in the first 
meeting, all tasks of the CMMN case plan (Figure 5) are also modeled in the BPCMN model (Figure 6).

Evaluating the BPCMN model in comparison to the CMMN model, the following can be stated. First, all behavioral aspects tasks and their dependencies have been adequately transformed to the new model. The sequence of tasks in structured process parts becomes directly visible in BPCMN. Thus, there is an improvement with regard to notation issue 4a (cf. Section 4). The lane concept is used to differentiate between roles and/or organizations. A combined model of the welfare office and the social care company (GeBEG) could be modeled if there is a method procedure available for that. We have an improvement with regard to issues 1 and 2 (cf. Section 4). However, the lane concept of BPMN is not well suited for collaborative tasks because a task can only be part of one lane. Solution suggestions could be a special collaboration lane that includes collaborative tasks and collaboration specific elements or a special association that connects individual tasks that are involved in a collaboration. A further evaluation of these suggestions as well as for BPCMN with regard to understandability would be required. Still, at the moment it can be stated, that there is no improvement with regard to issues 2.a and 2.b (cf. Section 4).

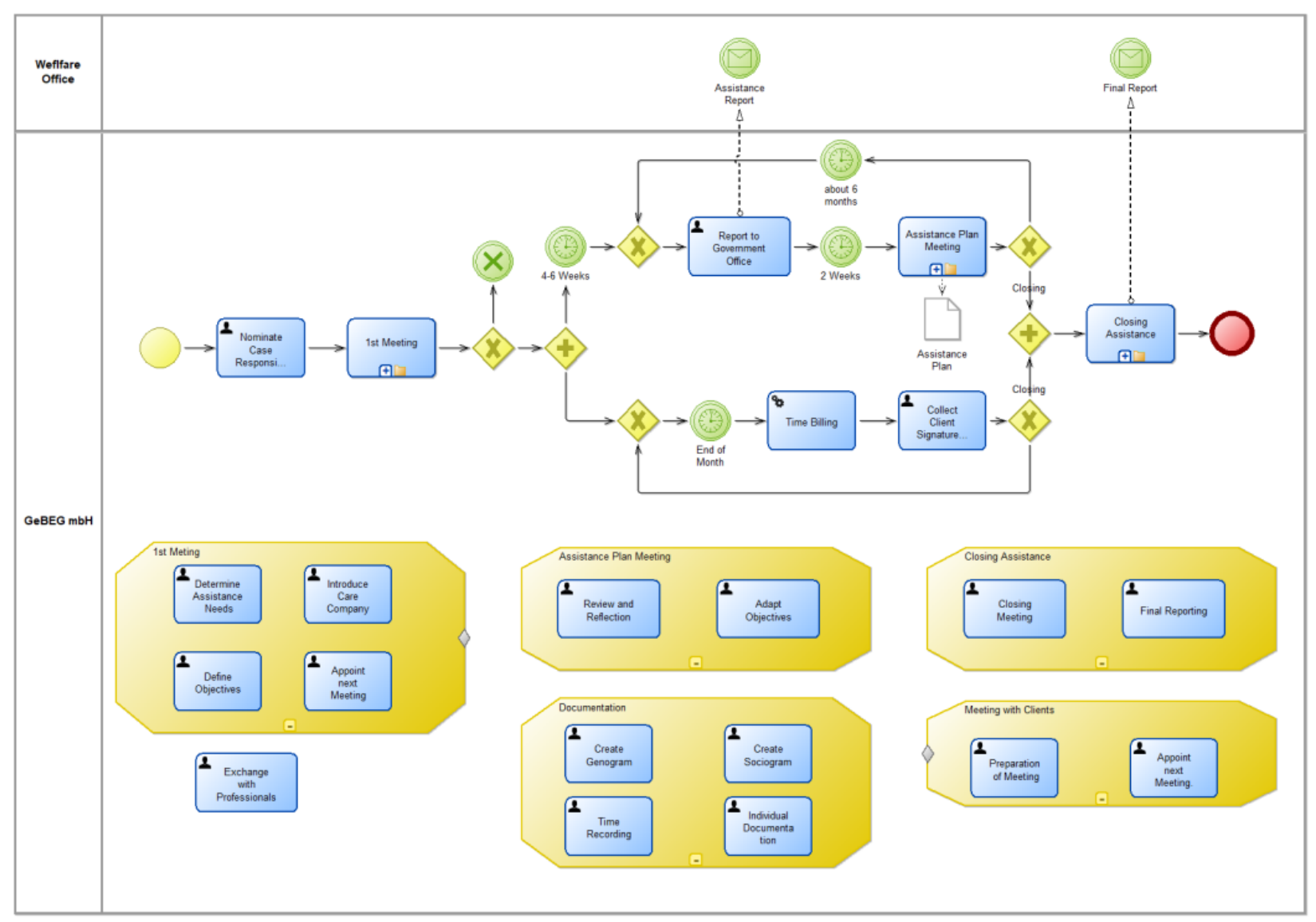

Figure 6. Process Template "Assistance for Child Upbringing” in BPCMN

Approach 2 for notation improvements - amending CMMN with new concepts - will not be discussed further on. CMMN additions suggested by Bukhsh et al. in [38] are either already part of the current CMMN notation or do not appropriately address the issues found in the case study. The development of new concepts and notation elements however should be considered only when the solutions that have already been suggested are properly evaluated. 


\section{Summary and Outlook}

This research addressed the question of whether the use of ACM is appropriate for social sector implementation or not. Subsequently, the central principles of ACM were presented, a distinction from BPM was made and a methodological support with extensions was created. In the following, the method was tested based on a case study, evaluated and, in accordance with the requirements of GeBEG, an included solution was developed to meet the needs of the company.

Regarding the overall achievement of the objectives, it could be stated that, by considering:

- the basic principles of ACM in combination with the suggested extensions,

- the findings of the case study, as well as

- the improvement approach of the case study modeling

evidences exist, that an application of ACM in the social sector seems appropriate. In addition, the case study indicated that workflows within the environment of social sector companies exist, which enable the use of case management.

With regard to the evaluation and further development of ACM in the social sector, case modeling method components were designed (Section 3.2) and fully applied, at least relating to the consulting case model of the study. According to the explanation of model weaknesses concerning ACM in Section 3.2 and the following sections, further research is necessary to generally:

- reduce the burden of case adjustments,

- make role models less complex, as well as

- design method components that allow the identification of cases and the evaluation of case models,

- improve CMMN understandability,

- provide appropriate means to include structured parts of the process into models.

In the special context of social institutions and ACM, investigations are necessary concerning:

- adequate support of definition and control of case objectives,

- refinement of the role model for appropriate fitting to the roles of $\mathrm{CM}$, as well as

- designing a method component for inter-organizational case models,

- modeling collaborative tasks, and

- modeling role based constraints.

In the context of the practical application, the step 1 (case group determination / screening, Section 2.3) was deliberately omitted since its validation in the context of the case study (Section 4) would not have been possible. Although GeBEG knows and uses CM, the participants did not consider a distinction of case groups meaningful.

With regard to notation issues, the free combination of CMMN and BPMN concepts as supported by BPCMN solves some of the found issues (cf. Section 5). The problem of modeling collaborations and role based constraints, however, needs further investigations. Still, a further evaluation of existing suggestions with regard to notation is required.

\section{References}

[1] N. Palmer, "Introduction," Mastering Unpredictable. How Adaptive Case Management Will Revolutionize Work That Knowledge Workers Get Things Done, K. D. Swenson ed., Meghan-Kiffer Press, Tampa, pp. 1-5, 2010.

[2] H. F. Sem, T. B. Pettersen, S. Carlsen, and G. J. Coll, "Patterns Boosting Adaptivity in ACM," OTM Confederated International Conferences "On the Move to Meaningful Internet Systems", On the Move to Meaningful Internet Systems (OTM) Workshops, LNCS, Springer, pp. 102-111, 2013. Available: https://doi.org/10.1007/978-3-642-41033-8_17 
[3] T. T. Hildebrandt, "EcoKnow: Effective, Co-created \& Compliant Adaptive Case Management for Knowledge Workers," Proceedings of the IEEE 22nd International Enterprise Distributed Object Computing Workshop (EDOCW), IEEE, pp. 9-11, 2018. Available: https://doi.org/10.1109/EDOCW.2018.00012

[4] M. Razavi, F. S. Aliee, and K. Badie, "An AHP-based approach toward enterprise architecture analysis based on enterprise architecture quality attributes," Knowledge and information systems, Springer, vol. 28, no. 2, pp. 449-472, 2011. Available: https://doi.org/10.1007/s10115-010-0312-1

[5] M. Benner-Wickner, W. Koop, M. Book, and V. Gruhn, "Supporting adaptive case management through semantic web technologies," Lecture Notes in Business Information Processing, Springer, vol. 256, pp. 65-77, 2016. Available: https://doi.org/10.1007/978-3-319-42887-1_6

[6] P. Herzog, B. Lantow, and J. Wichmann, "Adaptive Case Management - Creating a Case Template for Social Care Organizations," Joint Proceedings of the BIR 2019 Workshops and Doctoral Consortium co-located with the 18th International Conference on Perspectives in Business Informatics Research (BIR 2019), vol. 2443, pp. 83-71, 2019.

[7] H. Oesterle, J. Becker, and U. Frank, "Memorandum on design-oriented information sys-tems research," European Journal of Information Systems, vol. 20, no. 1, pp. 7-10, 2011. Available: https://doi.org/10.1057/ejis.2010.55

[8] E. Burns, "Case Management 101: 10 Things You Must Know About Case Management," Taming Unpredictable - Real World Adapt. Case Manag. Case Stud. Pract. Guid., Future Strategies Inc., Lighthouse Point, pp. 17-25, 2011.

[9] M. Kurz and C. Herrmann, "Adaptive Case Management - Anwendung des Business Process Management 2.0-Konzepts auf wissensintensive schwach strukturierte Geschäftsprozesse," Dienstorientierte IT - Systeme für hochflexible Geschäftsprozesse, 2011 (in German).

[10] N. Kostadinov and L. Yordanov, "Adaptive Case Management - Papiertiger oder die Antwort auf BPM Herausforderungen," 2014 (in German).

[11] M. Kurz, W. Schmidt, A. Fleischmann, and M. Lederer, "Leveraging CMMN for ACM: examining the applicability of a new OMG standard for adaptive case management," Proceedings of the 7th International Conference on Subject-Oriented Business Process Management, ACM, New York, article no. 4, 2015. Available: https://doi.org/10.1145/2723839.2723843

[12] D. McCauley, "Achieving Agility," Mastering Unpredictable. How Adaptive Case Management Will Revolutionize Work That Knowledge Workers Get Things Done, K. D. Swenson ed., Meghan-Kiffer Press, Tampa, pp. 257-276, 2010.

[13] H. F. Sem, S. Carlsen, and G. J. Coll, “On Two Approaches to ACM," Proceedings of the International Workshop on Business Process Management (BPM), LNBIP, Springer, vol. 132, pp. 12-23, 2013. Available: https://doi.org/10.1007/978-3-642-36285-9_3

[14] A. Adensamer and D. Rueckel, "Differences Between BPM and ACM Models for Process Execution," Proceedings of the International Symposium on Business Modeling and Software Design. Business Modeling and Software Design (BMSD), LNBIP, Springer, vol. 319, pp. 270-279, 2018. Available: https://doi.org/10.1007/978-3-319-94214-8_18

[15] L. Fischer, Taming the Excellence in Practice Series. Future Strategies Inc., Lighthouse Point, 2011.

[16] M. Kurz, "BPM 2.0: Selbstorganisation im Geschäftsprozessmanagement," Dienstorientierte IT-Systeme für hochflexible Geschäftsprozesse, University of Bamberg Press, Bamberg, pp. 193-216, 2011 (in German).

[17] G. Scheithauer and S. Hellmann, "Analysis and Documentation of Knowledge-Intensive Processes," Proceedings of the International Workshop on Business Process Management (BPM), LNBIP, Springer, vol. 132, pp. 3-11, 2013. Available: https://doi.org/10.1007/978-3-642-36285-9_2

[18] P. Löcherbach et al. Case Management: Fall- und Systemsteuerung in der Sozialen Arbeit. Ernst Reinhardt Verlag, München, Basel, 2005 (in German).

[19] V. Brinkmann, Case Management. Springer Fachmedien, Heidelberg, 2010. Available: https://doi.org/10.1007/978-3-8349-8589-7

[20] B. Michel-Schwartze, Methodenbuch Soziale Arbeit. 2nd ed., VS Verlag für Sozialwissenschaften, Wiesbaden, 2009 (in German). Available: https://doi.org/10.1007/978-3-531-91453-4

[21] I. Kollak and S. Schmidt, Fallübungen Care und Case Management. Springer, Heidelberg, 2015 (in German). Available: https://doi.org/10.1007/978-3-642-41725-2 
[22] B. Müller, Sozialpädagogisches Können: ein Lehrbuch zur multiperspektivischen Fallarbeit. Lambertus, Freiburg, 1993 (in German).

[23] M. Briggs, P. P. Valentijn, J. A. Thiyagarajan, and I. Aurajo De Carvalho, "Elements of integrated care approaches for older people: A review of reviews," BMJ Open, vol. 8, no. 4, British Medical Association, London, pp. 1-13, 2018. Available: https://doi.org/10.1136/bmjopen-2017-021194

[24] J. Stokes, L. Riste, and S. Cheraghi-Sohi, "Targeting the 'right' patients for integrated care: Stakeholder perspectives from a qualitative study," Journal of Health Services Research and Policy, SAGE, vol. 23, no. 4, 2018. Available: https://doi.org/10.1177/1355819618788100

[25] M. Neuffer, Case Management - Soziale Arbeit mit Einzelnen und Familien. Beltz Juventa, Weinheim, 2012 (in German).

[26] I. Routis, M. Nikolaidou, and D. Anagnostopoulos, "Using CMMN to model social processes," Proceedings of the 15th International Conference on Business Process Management (BPM), LNBIP, Springer, vol. 308, pp. 335-347, 2017. Available: https://doi.org/10.1007/978-3-319-74030-0_25

[27] C. von Reibnitz, Case Management: praktisch und effizient. Springer Medizin Verlag, Berlin, 2009 (in German). Available: https://doi.org/10.1007/978-3-642-01317-1

[28] B. Michel-Schwartze, "Modernisierungen" methodischen Handelns in der Sozialen Arbeit. VS Verlag für Sozialwissenschaften/GWV Fachverlage GmbH, Wiesbaden, 2010 (in German). Available: https://doi.org/10.1007/978-3-531-92588-2

[29] H. R. Motahari-Nezhad and K. D. Swenson, "Adaptive Case Management: Overview and Research Challenges," Proceedings of the IEEE 15th Conference on Business Informatics (CBI), IEEE, pp. 264-269, 2013. Available: https://doi.org/10.1109/CBI.2013.44

[30] G. Goldkuhl, M. Lind, and U. Seigerroth, "Method integration: the need for a learning perspective," IEEE Proceedings-Software, vol. 145, no. 4, pp. 113-118, 1998. Available: https://doi.org/10.1049/ip-sen:19982197

[31] C. Herrmann and M. Kurz, "Adaptive case management: supporting knowledge intensive processes with IT systems," S-BPM ONE-Learning by Doing-Doing by Learning, Springer, pp. 80-97, 2011. Available: https://doi.org/10.1007/978-3-642-23471-2_6

[32] T. Wilde and T. Hess, "Forschungsmethoden der Wirtschaftsinformatik," Wirtschaftsinformatik, Springer, vol. 49, no. 4, pp. 280-287, 2011 (in German). Available: https://doi.org/10.1007/s11576-007-0064-Z

[33] L. A. Palinkas, S. M. Horwitz, and C. A. Green, "Purposeful sampling for qualitative fata collection and analysis in mixed method implementation research," Administration and Policy in Mental Health and Mental Health, Springer, vol. 42, no. 5, pp. 533-544, 2016. Available: https://doi.org/10.1007/s10488-013-0528-y

[34] N. Prenner, "Ein Werkzeug zur Erfassung von Geschäftsprozessen durch szenariobasierte Interviews," Ph.D. dissertation, Gottfried Wilhelm Leibniz Universität Hannover, 2015 (in German)

[35] B. Trinczek, "Informationssysteme im Gesundheitswesen,” Medizinische Fakultät Münster, Münster, 2015 (in German).

[36] T. Hildebrandt, R. R. Mukkamala, and T. Slaats, "Designing a cross-organizational case management system using dynamic condition response graphs," Proceedings of the 15th IEEE International Enterprise Distributed Object Computing Conference (EDOC), IEEE, pp. 161-170, 2011. Available: https://doi.org/10.1109/EDOC.2011.35

[37] M. Kurz, "Taming diversity: A distributed acm-based approach for cross-enterprise knowledge work," Proceedings of the IEEE/WIC/ACM International Joint Conferences on Web Intelligence (WI) and Intelligent Agent Technologies (IAT), IEEE, vol. 3, pp. 87-91, 2013. Available: https://doi.org/10.1109/WI-IAT.2013.156

[38] Z. A. Bukhsh, M. van Sinderen, N. S. Klaas, and D. Quartel, "Understanding modeling requirements of unstructured business processes," ICETE 2017 - Proceedings of the 14th International Joint Conference on eBusiness and Telecommunications, vol. 2, 2017.

[39] I. Bider, “Towards Process Improvement for Case Management," Reichert, M., Reijers, H. A. (eds.) Business Process Management Workshops, Lecture Notes in Business Information Processing, Springer, vol. 256, pp. 96-107, 2016. Available: https://doi.org/10.1007/978-3-319-42887-1_9

[40] M. Hauder, R. Kazman, and F. Matthes, "Empowering End-Users to Collaboratively Structure Processes for Knowledge Work," Abramowicz, W. (ed.) Business Information Systems, LNBIP, Springer, vol. 208, pp. 207219, 2015. Available: https://doi.org/10.1007/978-3-319-19027-3_17 
[41] B. Lantow, "Adaptive Case Management - A Review of Method Support," Proceedings of the 11th IFIP WG 8.1. Working Conference, PoEM, Lecture Notes in Business Information Processing, Springer, vol. 335, pp. 157-171, 2018. Available: https://doi.org/10.1007/978-3-030-02302-7_10

[42] K. Hinkelmann, "Business process flexibility and decision-aware modeling - The knowledge work designer," Domain-Specific Conceptual Modeling: Concepts, Methods and Tools, pp. 397-414, 2016. Available: https://doi.org/10.1007/978-3-319-39417-6 18

[43] K. Hinkelmann, A. Pierfranceschi, and E. Laurenzi, "The knowledge work designer - Modelling process logic and business logic." Lecture Notes in Informatics, Proceedings - Series of the Gesellschaft fur Informatik (GI), P255, 2016.

[44] I. Bider, A. Jalali, and J. Ohlsson, “Adaptive Case Management as a Process of Construction of and Movement in a State Space," On the Move to Meaningful Internet Systems: OTM 2013 Workshops, LNCS, Springer, vol. 8186, pp. 155-165, 2013. Available: https://doi.org/10.1007/978-3-642-41033-8_22 